\title{
Biological contamination of soils in urbanized ecosystems by Toxocara sp. eggs.
}

\author{
Olga Maslennikova ${ }^{1}$, Viktoriya Erofeeva $^{2,3}$ \\ ${ }^{1}$ Vyatka State Agricultural Academy, Kirov, 610017, Russia \\ ${ }^{2}$ Peoples' Friendship University of Russia (RUDN University), Faculty of Ecology, 6 \\ Miklukho-Maklaya St, Moscow, 117198, Russian Federation \\ ${ }^{3}$ Moscow Technical University of Communications and Informatics, Moscow, 111024, \\ Russia
}

\begin{abstract}
As a result of the study of three sites (two city parks and a special area for walking dogs) on the contamination of Toxocara sp. eggs it was found that $28.0 \pm 2.3 \%$ of the studied fecal samples from the territories of the Kirov Park were infected with Toxocara eggs, $21.0 \pm 3.6 \%$ of fecal samples from the territory of the Park of the 50th anniversary of the Komsomol and $7.0 \pm 0.4 \%$ of fecal samples were infected with Toxocara eggs selected at a specially equipped dog walking area in the Metrograd residential complex in Kirov. The average rate of dogs which were infected by Toxocara (EI) was $18.7 \pm 6.2 \%$. The average rate of contamination of soil by eggs Toxocara in the study sites amounted to $34.6 \%$. Contamination of soil samples with eggs of Toxocara sp. in parks was $45.6 \%$ and $45.8 \%$, respectively, and in the dog walking area it was $12 \%$. The largest number of dogs, including stray ones, were registered in the parks: $74.8 \pm 7.1$ and $62.8 \pm 7.0$ individuals, respectively. There were no stray individuals in the dog walking area, and there were $21.6 \pm 1.0$ individuals over the entire study period.
\end{abstract}

\section{Introduction}

At present, biological pollution of the environment is becoming an environmental problem on the territory of large cities. Biological pollution is the contribution to the environment and reproduction of microorganisms in it, the presence of eggs of parasites that cause diseases of humans and farm animals. Biological contamination of the environment with helminth eggs from domestic animals is particularly dangerous.

The soil of cities undergoes a huge biological pollution as a result of unauthorized placement of a huge number of feces of dogs and cats, contaminated with helminth eggs. The main sources of soil contamination by feces of urbanized territories are the increasing population of decorative, service, hunting breeds of dogs, as well as cats of various breeds, and increasing populations of stray animals. Infected dogs and cats, polluting objects of the external environment by helminth eggs with feces, endanger all those around them. Carnivores, especially dogs infected with parasites, pose a direct threat of infection and disease in humans [1]. 
Pollution of the natural environment with helminth eggs is an acute environmental problem in many major Russian cities, including Kirov [2-6].

A person can be infected with 32 types of helminths that are common to animals and humans [2]. One of the dangerous worms to humans, especially children, are Toxocara (Toxocara canis and Toxocara mystax). Sources of infection of people are pets (cats and dogs). Invasive diseases of cats and dogs are registered everywhere, especially among stray dogs.

Toxocara eggs are very resistant to adverse environmental factors, Toxocara eggs can persist in the soil for a long time and resist the action of various chemicals. Cockroaches and flies can participate in the spread of Toxocara eggs as well as other helminths, and earthworms play the role of paratenic hosts [7-9].

The aim of our study is to assess the level of bio- contamination of environmental objects (soil) by Toxocara sp. eggs in places where dogs are walking in parks in Kirov.

\section{Materials and methods}

The research was conducted from 01.05 .2017 to 31.05 .2018 in a specialized laboratory complex.

The collection of material for research was carried out on three sites with an area of $100 \times 100 \mathrm{~m}$ in the territory of Kirov: the Kirov Park; the Park of the 50th anniversary of the Komsomol; dog walking area in the residential area of Metrograd. The objects of research were 300 depersonalized canine excrement and 45 combined soil samples taken at these sites. Test sites were laid in areas with homogeneous soil and vegetation cover. Soil sampling was carried out in accordance with the methods of sanitary and parasitological research (2000).

The method of standard visual accounting was applied to account for the number of dogs on three sites [10]. The study of depersonalized dog excrement for the presence of eggs was performed by the Fulleborn method [4]. The extent of infestation (EI) was calculated. The method of N. A. Romanenko (1996) was used to study the soil for helminth eggs.

Statistical processing of the findings was carried out using the Excel computer program.

\section{Results}

We calculated the number of walking dogs on all three sites in Kirov from May to September 2017. The findings is shown in table 1.

Table 1. Calculated the number of walking dogs on all three sites in Kirov from May to September 2017.

\begin{tabular}{|l|c|c|c|c|c|c|}
\hline Place of research & May & June & July & August & $\begin{array}{c}\text { Septembe } \\
\text { r }\end{array}$ & $\begin{array}{c}\text { The } \\
\text { average } \\
\text { number } \\
\text { of dogs }\end{array}$ \\
\hline The Kirov Park & $85.0 \pm 9.4$ & $65.0 \pm 9,7$ & $94.0 \pm 12.2$ & $76.0 \pm 13.0$ & $54.0 \pm 8.1$ & $74.8 \pm 7.1$ \\
\hline $\begin{array}{l}\text { The Park of the } \\
\text { 50th anniversary } \\
\text { of the Komsomol }\end{array}$ & $78.0 \pm 8.7$ & $48.0 \pm 6.9$ & $72.0 \pm 12.1$ & $72.0 \pm 8.7$ & $44.0 \pm 7.4$ & $62.8 \pm 7.0$ \\
\hline $\begin{array}{l}\text { The dog walking } \\
\text { area }\end{array}$ & $23.0 \pm 3.0$ & $20.0 \pm 4.3$ & $23.0 \pm 2.7$ & $21.0 \pm 2.6$ & $21.0 \pm 2.9$ & $21.6 \pm 1.0$ \\
\hline
\end{tabular}


According to these findings, the largest number of dogs were registered in the Kirov Park it is $74.8 \pm 7.1$ individuals, in July this indicator reached $94.0 \pm 12.2$ individuals. In the Park of the 50th anniversary of the Komsomol the average number of dogs for the accounting period was $62.8 \pm 7.0$ individuals. In June and September, the smallest number of dogs were counted -48 and 44 , respectively. The number of dogs on the dog-walking site for the entire period of research was only $21.6 \pm 1.0$ individuals.

Percentage of occurrence of the invasive origin of helminths (eggs) in soil samples in the Kirov Park is shown in picture 1.

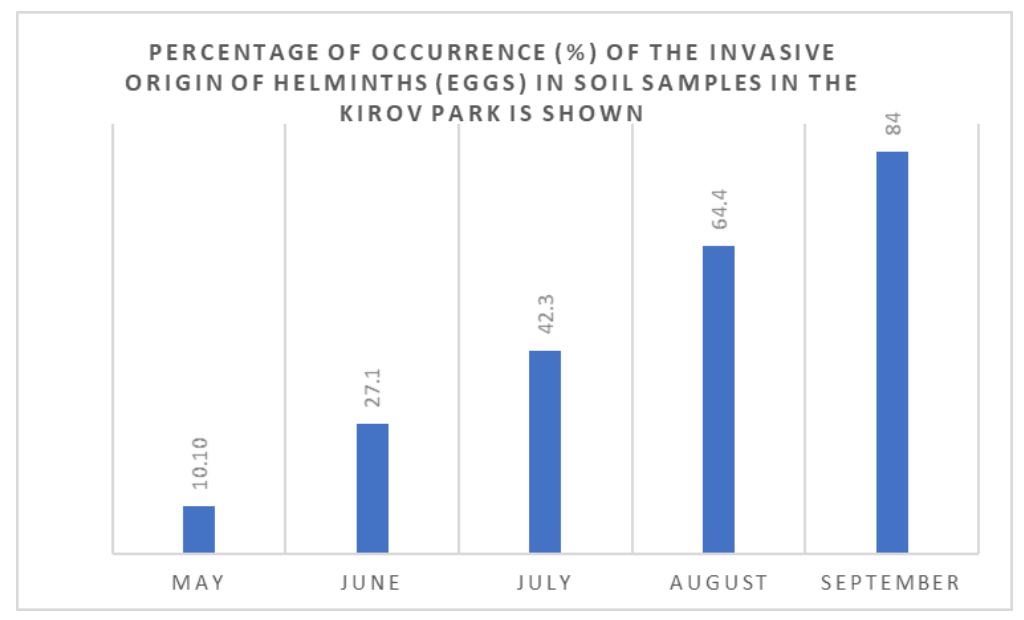

Fig.1. Percentage of occurrence of the invasive origin of Toxocara sp. in soil samples in the Kirov Park is shown

According to the results of the research, positive findings of toxocar eggs were recorded throughout the experiment, and there was an increase in the number of positive samples from May to September. The average rate of soil contamination in the Kirov Park is $45.6 \%$. The highest percentage of soil contamination was registered in September $84.0 \%$, the lowest in may-10.1\%.

The percentage occurrence of eggs of Toxocara sp. in soil samples in the Park of the 50th anniversary of the Komsomol is shown in picture 2. In this park the contamination of soil with eggs of Toxocara sp., as in the Kirov Park, increased from May to September. The average rate of soil contamination was $45.8 \%$. The highest percentage of soil contamination was registered in August and September $(70.8 \% ; 76.1 \%$, respectively) and the lowest in may $-8.7 \%$. 


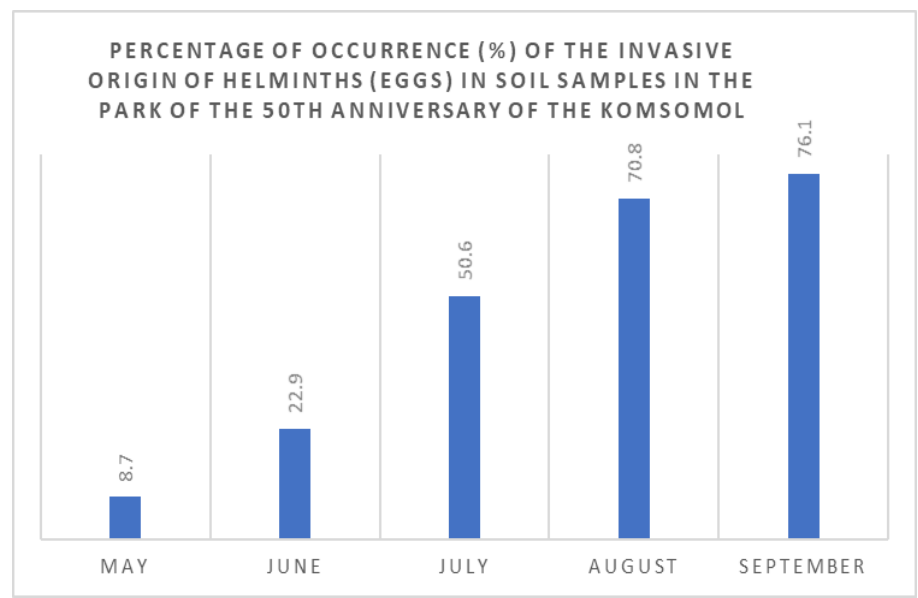

Fig.2. Percentage of occurrence of the invasive origin of Toxocara sp. in soil samples in the Park of the 50th anniversary of the Komsomol

The average rate of soil contamination at the dog walking area in the Metrograd residential complex is $12 \%$. There was an increase in the number of positive samples with the registration of Toxocara sp eggs from May to September. The highest percentage of soil contamination was registered in August and September $(17.5 \% ; 25.7 \%$, respectively) and the lowest in May and June $(1.0 \%, 3.6 \%$, respectively). In September soil contamination with Toxocara eggs was the highest and reached an average of $63.2 \%$ for three sites, due to the accumulation of infestation and its preservation.

The number of eggs per $1 \mathrm{~kg}$ of soil was calculated for three sites. The results of studies of the degree of soil contamination by Toxocara eggs on the territory of the study sites are presented in table 2 .

Table 2. The results of studies of the degree of soil contamination by Toxocara sp. on the territory of the study sites

\begin{tabular}{|l|c|c|c|c|}
\hline \multicolumn{1}{|c|}{ Sampling } & $\begin{array}{c}\text { The Kirov } \\
\text { Park }\end{array}$ & $\begin{array}{c}\text { The Park of the } \\
\text { 50th } \\
\text { anniversary of } \\
\text { the Komsomol }\end{array}$ & $\begin{array}{c}\text { The Metrograd } \\
\text { residential } \\
\text { complex in } \\
\text { Kirov }\end{array}$ & $\begin{array}{c}\text { Average } \\
\text { value }\end{array}$ \\
\hline $\begin{array}{l}\text { Toxocara } \\
\text { eggs, ind./kg }\end{array}$ & $11.1 \pm 2.4$ & $6.5 \pm 2.0$ & $1.2 \pm 1.0$ & $6.3 \pm 2.9$ \\
\hline
\end{tabular}

According to SanPiN 2.1.7.1287-03 "Sanitary and epidemiological requirements for soil quality" [11] in the total number of helminth eggs per $1 \mathrm{~kg}$ of soil, the Kirov Park is classified as dangerous (more than 10 eggs per $1 \mathrm{~kg}$ of soil), the Park of the 50th anniversary of the Komsomol and the dog walking area in the Metrograd residential complex in Kirov are classified as moderately dangerous (less than 10 eggs per $1 \mathrm{~kg}$ of soil).

The study of 300 samples of depersonalized dog feces found that the average rate of infection of dogs Toxocara (EI) was $18.7 \pm 6.2 \%$. The findings on contamination of dog excrement with Toxocara canis eggs (\%) in Kirov are presented in table 3.

Table 3. The findings on contamination of dog excrement with Toxocara sp. eggs (\%) in Kirov

\begin{tabular}{|c|c|c|c|}
\hline Sampling & $\begin{array}{c}\text { The Kirov } \\
\text { Park }\end{array}$ & $\begin{array}{c}\text { The Park of the } \\
\text { 50th anniversary } \\
\text { of the Komsomol }\end{array}$ & $\begin{array}{c}\text { The Metrograd } \\
\text { residential } \\
\text { complex in Kirov }\end{array}$ \\
\hline $\begin{array}{c}\text { The number of positive } \\
\text { samples of excrement, \% }\end{array}$ & $28.0 \pm 2.3$ & $21.0 \pm 3.6$ & $7.0 \pm 0.4$ \\
\hline
\end{tabular}


In the course of laboratory research, it was found that toxocar eggs infected $28 \pm 2.3 \%$ of the studied fecal samples from the territories of the Kirov Park, $21 \pm 3.6 \%$ of the studied fecal samples from the territory of the Park of the 50th anniversary of the Komsomol and $7 \pm 0.4 \%$ of the studied fecal samples were infected with Toxocara eggs selected at a specially equipped dog walking area in the Metrograd residential complex in Kirov.

\section{Discussion}

Given the high number of dogs in the parks of Kirov, according to the conducted research, it can be assumed that the city's ecosystem is experiencing a high degree of pollution from animal biological waste.

The incidence of toxocarosis in children and adults depends directly on the contamination of the soil with toxocar eggs, which are spread by dogs. The increase in the proportion of Toxocara eggs found indicates an increasing risk of infection of the population of Kirov with toxocarosis.

The results of the research showed that the soil of different types of objects in Kirov has characteristic differences in the degree of contamination with t Toxocara eggs. The average contamination of soil by Toxocara eggs in the tudy sites amounted to 34.6\%. Soil from the territories of Kirov Park and the Park of the 50th anniversary of the Komsomol was contaminated to the maximum extent, which is due to the presence of a large number of stray and neglected dogs in these places $(45.6 \%$ and $45.8 \%$ of the tested samples were positive). Low indicators of soil contamination with Toxocara eggs $-12 \%$ were observed on a specially equipped dog walking area in the Metrograd residential complex in Kirov, which is due to the protection of the territory from the penetration of stray and homeless dogs, the novelty of the construction and compliance with sanitary and epidemiological rules of the site maintenance.

According to research by M. V. Guzeeva [3], conducted in the Zelenograd administrative district of the Moscow region, the percentage of soil contamination with toxocar eggs in the city on average is $13.5 \pm 1.1$, playgrounds of residential buildings amounted to $14.8 \pm 1.7 \%$, sandboxes of children's educational institutions $-11.0 \pm 1.5 \%$. The maximum indicators of the level of soil contamination with toxocar eggs were found at dog walking sites-35.1 $\pm 6.3 \%$ [3].

We found that in May, soil contamination with Toxocara eggs at three sites was the lowest and amounted to $6.6 \%$, which is due to the death of a large number of eggs in the winter at low temperatures (frosts reached $-38^{\circ} \mathrm{C}$ ). In the summer, the contamination of soil by toxocar eggs increased to $34.3 \%$, due to the high temperatures and moist soil.

Comparison of soil contamination and dog excrement with eggs of Toxocara sp. showed a directly proportional relationship - soil contamination with Toxocara eggs directly depends on soil contamination with canine excrement.

According to L. V. Shishkanova [6], the intensity of contamination of the substrate with Toxocara canis eggs in the Krasnodar region is 3.3 eggs $/ \mathrm{kg}$, in the Rostov region-3.7 eggs $/ \mathrm{kg}$, in the Republic of Adygeya - 5.2 eggs $/ \mathrm{kg}$, and their viability is $70.8 \%, 62.3 \%$ and $67.1 \%$.

The intensity of contamination of the external environment with helminth eggs depends largely on the sanitary improvement of settlements, on the sanitary culture and level of education of the population, the level of infection with helminths of dogs and the conditions of their maintenance.

\section{Conclusions}


Dog records showed a large number of stray dogs in parks. The low number of dogs and the absence of stray dogs were registered on a specially equipped dog walking area in the Metrograd residential complex.

According to the existing rules of sanitary and hygienic assessment of the soil for the total number of helminth eggs per $1 \mathrm{~kg}$ of soil, the Kirov Park is classified as dangerous, the Park of the 50th anniversary of the Komsomol and the dog walking area in the Metrograd residential complex in Kirov are classified as moderately dangerous. The average rate of infection of dogs with toxocariasis $18.7 \pm 6.2 \%$.

\section{References}

1. A.N. Volichev, Tr. Vseros. Institute of helminthol., 39, 55-64 (2003)

2. I.A. Arkhipov, O.A. Zeynalov, L.M. Kokorina, D.A. Avdanina, S.V. Likhotina, Russian Veterinary Journal, 2, 26-30 (2005)

3. M.V. Guzeeva, The role and place of rare helminthiases in parasitic pathology in Russia (2009)

4. G. A. Kotelnikov, Helminthological studies of animals and the environment, (1984)

5. V.V. Erofeeva, O.V. Maslennikova, Modern problems of science and education, 3, 573 (2015)

6. L.V. Shishkanova, Toxocariasis in the south of Russia (2011)

7. S. Okoshi, M. Usui, Jpn. J. Vet. Sci, 30, 151-166 (1968)

8. V.V. Erofeeva, O.V. Maslennikova, Hygiene and sanitation, 8, 897-902 (2019)

9. O.V. Maslennikova, V.V. Erofeeva, Modern problems of science and education, 5, 683 (2015)

10. A. S. Severtsev, A.O. Vereshchagin, A.D. Poyarkov et al., Problems of research of a domestic dog: Materials of a meeting, 95-114 (2006)

11. Methods of sanitary-parasitological research (2000) 